WORKSHOP ON EDUCATIONAL INNOVATION

IN ARCHITECTURE JIDA'21

JORNADES SOBRE INNOVACIÓ

DOCENT EN ARQUITECTURA JIDA'21

ESCUELA TÉCNICA SUPERIOR DE ARQUITECTURA DE VALLADOLID 11 Y 12 DE NOVIEMBRE DE 2021 
Organiza e impulsa GILDA (Grupo para la Innovación y Logística Docente en la Arquitectura), en el marco del proyecto RIMA (Investigación e Innovación en Metodologías de Aprendizaje), de la Universitat Politècnica de Catalunya - BarcelonaTech (UPC) y el Institut de Ciències de l'Educació (ICE). http://revistes.upc.edu/ojs/index.php/JIDA

\section{Editores}

Daniel García-Escudero, Berta Bardí i Milà

\section{Revisión de textos}

Alba Arboix, Jordi Franquesa, Joan Moreno

\section{Edita}

Iniciativa Digital Politècnica Oficina de Publicacions Acadèmiques Digitals de la UPC

ISBN 978-84-9880-969-5 (IDP-UPC)

elSSN 2462-571X

(c) de los textos y las imágenes: los autores

(C) de la presente edición: Iniciativa Digital Politècnica Oficina de Publicacions

Acadèmiques Digitals de la UPC

Esta obra está sujeta a una licencia Creative Commons:

Reconocimiento - No comercial - SinObraDerivada (cc-by-nc-nd):

http://creativecommons.org/licences/by-nc-nd/3.0/es

https://creativecommons.org/licenses/by-nc-nd/4.0/

Cualquier parte de esta obra se puede reproducir sin autorización

pero con el reconocimiento y atribución de los autores.

No se puede hacer uso comercial de la obra y no se puede alterar, transformar o hacer obras derivadas. 


\section{JIDA}

\section{Comité Organizador JIDA'21}

\section{Dirección y edición}

\section{Berta Bardí i Milà (UPC)}

Dra. Arquitecta, Departamento de Proyectos Arquitectónicos, ETSAB-UPC

Daniel García-Escudero (UPC)

Dr. Arquitecto, Departamento de Proyectos Arquitectónicos, ETSAB-UPC

\section{Organización}

\section{Nieves Fernández Villalobos (UVA)}

Dra. Arquitecta, Teoría de la Arquitectura y Proyectos Arquitectónicos, ETSAVA

Jordi Franquesa (UPC)

Dr. Arquitecto, Departamento de Urbanismo y Ordenación del Territorio, ETSAB-UPC Joan Moreno Sanz (UPC)

Dr. Arquitecto, Departamento de Urbanismo y Ordenación del Territorio, ETSAB-UPC, ETSAV-UPC

\section{Gemma Ramón-Cueto (UVA)}

Dra. Arquitecta, Construcciones Arquitectónicas, Ingeniería del Terreno y Mecánica de los Medios continuos y Teoría de Estructuras, Secretaria Académica ETSAVA

Jorge Ramos Jular (UVA)

Dr. Arquitecto, Teoría de la Arquitectura y Proyectos Arquitectónicos, ETSAVA

Judit Taberna (UPC)

Arquitecta, Departamento de Representación Arquitectónica, ETSAB-UPC

\section{Coordinación}

\section{Alba Arboix}

Dra. Arquitecta, Teoría e Historia de la Arquitectura y Técnicas de la Comunicación, ETSAB-UPC

\section{Comunicación}

Eduard Llorens i Pomés

ETSAB-UPC 


\section{JIDA}

\section{Comité Científico JIDA'21}

Luisa Alarcón González

Dra. Arquitecta, Proyectos Arquitectónicos, ETSA-US

Eusebio Alonso García

Dr. Arquitecto, Teoría de la Arquitectura y Proyectos Arquitectónicos, ETSAVA-UVA

Darío Álvarez Álvarez

Dr. Arquitecto, Teoría de la Arquitectura y Proyectos Arquitectónicos, ETSAVA-UVA

Antonio Álvaro Tordesillas

Dr. Arquitecto, Urbanismo y Representación de la Arquitectura, ETSAVA-UVA

Atxu Amann Alcocer

Dra. Arquitecta, Ideación Gráfica Arquitectónica, ETSAM-UPM

Javier Arias Madero

Dr. Arquitecto, Construcciones Arquitectónicas, ETSAVA-UVA

Irma Arribas Pérez

Dra. Arquitecta, Diseño, Instituto Europeo de Diseño, IED Barcelona

Raimundo Bambó

Dr. Arquitecto, Urbanismo y ordenación del territorio, EINA-UNIZAR

Iñaki Bergera

Dr. Arquitecto, Proyectos Arquitectónicos, EINA-UNIZAR

Jaume Blancafort

Dr. Arquitecto, Arquitectura y Tecnología de la Edificación, ETSAE-UPCT

Enrique Manuel Blanco Lorenzo

Dr. Arquitecto, Proyectos Arquitectónicos, Urbanismo y Composición, ETSAC-UdC

Raúl Castellanos Gómez

Dr. Arquitecto, Proyectos Arquitectónicos, ETSA-UPV

Nuria Castilla Cabanes

Dra. Arquitecta, Construcciones arquitectónicas, ETSA-UPV

David Caralt

Arquitecto, Universidad San Sebastián, Sede Concepción, Chile

Rodrigo Carbajal Ballell

Dr. Arquitecto, Proyectos Arquitectónicos, ETSA-US

Eva Crespo

Dra. Arquitecta, Tecnología de la Arquitectura, ETSAB-UPC

Silvia Colmenares

Dra. Arquitecta, Proyectos Arquitectónicos, ETSAM-UPM

Còssima Cornadó Bardón

Dra. Arquitecta, Tecnología de la Arquitectura, ETSAB-UPC

Eduardo Delgado Orusco

Dr. Arquitecto, Proyectos Arquitectónicos, EINA-UNIZAR

Carmen Díez Medina

Dra. Arquitecta, Composición, EINA-UNIZAR

Sagrario Fernández Raga

Dra. Arquitecta, Teoría de la Arquitectura y Proyectos Arquitectónicos, ETSAVA-UVA

Arturo Frediani Sarfati

Dr. Arquitecto, Proyectos, Urbanismo y Dibujo, EAR-URV 


\section{JIDA}

Jessica Fuentealba Quilodrán

Dra. Arquitecta, Departamento Diseño y Teoría de la Arquitectura, Universidad del Bio-Bío, Concepción, Chile

Noelia Galván Desvaux

Dra. Arquitecta, Urbanismo y Representación de la Arquitectura, ETSAVA-UVA

María Jesús García Granja

Arquitecta, Departamento de Arte y Arquitectura, eAM'-UMA

Pedro García Martínez

Dr. Arquitecto, Arquitectura y Tecnología de la Edificación, ETSAE-UPCT

Mariona Genís Vinyals

Dra. Arquitecta, BAU Centre Universitari de Disseny, UVic-UCC

Eva Gil Lopesino

Arquitecta, Proyectos Arquitectónicos, ETSAM-UPM

María González

Arquitecta, Proyectos Arquitectónicos, ETSA-US

Arianna Guardiola Víllora

Dra. Arquitecta, Mecánica de los Medios Continuos y Teoría de Estructuras, ETSA-UPV

David Hernández Falagán

Dr. Arquitecto, Teoría e historia de la arquitectura y técnicas de comunicación, ETSAB-UPC

José $M^{a}$ Jové Sandoval

Dr. Arquitecto, Teoría de la Arquitectura y Proyectos Arquitectónicos, ETSAVA-UVA

Íñigo Lizundia Uranga

Dr. Arquitecto, Construcciones Arquitectónicas, ETSA EHU-UPV

Carlos Labarta

Dr. Arquitecto, Proyectos Arquitectónicos, EINA-UNIZAR

Emma López Bahut

Dra. Arquitecta, Proyectos, Urbanismo y Composición, ETSAC-UdC

Juanjo López de la Cruz

Arquitecto, Proyectos Arquitectónicos, ETSA-US

Alfredo Llorente Álvarez

Dr. Arquitecto, Construcciones Arquitectónicas, Ingeniería del Terreno y Mecánicas de los Medios

Continuos y Teoría de Estructuras, ETSAVA-UVA

Magda Mària Serrano

Dra. Arquitecta, Proyectos Arquitectónicos, ETSAV-UPC

Cristina Marieta Gorriti

Dra. Arquitecta, Ingeniería Química y del Medio Ambiente, EIG UPV-EHU

Zaida Muxí Martínez

Dra. Arquitecta, Urbanismo y ordenación del territorio, ETSAB-UPC

David Navarro Moreno

Dr. Ingeniero de Edificación, Arquitectura y Tecnología de la Edificación, ETSAE-UPCT

Amadeo Ramos Carranza

Dr. Arquitecto, Proyectos Arquitectónicos, ETSA-US

Patricia Reus

Dra. Arquitecta, Arquitectura y Tecnología de la Edificación, ETSAE-UPCT

Silvana Rodrigues de Oliveira

Dra. Arquitecta, Proyectos Arquitectónicos, ETSA-US 
Carlos Rodríguez Fernández

Dr. Arquitecto, Teoría de la Arquitectura y Proyectos Arquitectónicos, ETSAVA-UV

Jaume Roset Calzada

Dr. Físico, Física Aplicada, ETSAB-UPC

Borja Ruiz-Apilánez Corrochano

Dr. Arquitecto, UyOT, Ingeniería Civil y de la Edificación, EAT-UCLM

Patricia Sabín Díaz

Dra. Arquitecta, Proyectos Arquitectónicos, Urbanismo y Composición, ETSAC-UdC

Mara Sánchez Llorens

Dra. Arquitecta, Ideación Gráfica Arquitectónica, ETSAM-UPM

Luis Santos y Ganges

Dr. Urbanista, Urbanismo y Representación de la Arquitectura, ETSAVA-UVA

Carla Sentieri Omarrementeria

Dra. Arquitecta, Proyectos Arquitectónicos, ETSA-UPV

Marta Serra Permanyer

Dra. Arquitecta, Teoría e Historia de la Arquitectura y Técnicas de la Comunicación, ETSAV-UPC

Sergio Vega Sánchez

Dr. Arquitecto, Construcción y Tecnologías Arquitectónicas, ETSAM-UPM

José Vela Castillo

Dr. Arquitecto, Culture and Theory in Architecture and Idea and Form, IE School of Architecture and

Design, IE University, Segovia

Ferran Ventura Blanch

Dr. Arquitecto, Proyectos Arquitectónicos, eAM'-UMA

Isabel Zaragoza de Pedro

Dra. Arquitecta, Representación Arquitectónica, ETSAB-UPC 


\section{ÍNDICE}

1. Hábitat, paisaje e infraestructura en el entorno de la presa de El Grado (Huesca) Habitat, landscape and infrastructure in the surroundings of El Grado dam (Huesca). Estepa Rubio, Antonio; Elía García, Santiago.

2. Aprendiendo a dibujar confinados: un método, dos entornos. Learning to draw in confinement: one method, two environments. Salgado de la Rosa, María Asunción; Raposo Grau, Javier Fco, Butragueño Díaz-Guerra, Belén.

3. Aprendizaje basado en proyecto en la arquitectura a través de herramientas online. Project-based learning in architecture through online tools. Oregi, Xabat; Rodriguez, Iñigo; Martín-Garín, Alexander.

4. Técnicas de animación para la comprensión y narración de procesos de montaje constructivos. Animation techniques for understanding and storytelling of construction assembly processes. Maciá-Torregrosa, María Eugenia.

5. Desarrollo del Programa de Aprendizaje y Servicio en diversas asignaturas del grado de arquitectura. Development of the Learning and Service Program in various subjects of the degree of architecture. Coll-Pla, Sergio; Costa-Jover, Agustí.

6. Integración de estándares sostenibles en proyectos arquitectónicos. Integration of sustainable standards in architectural projects. Oregi, Xabat.

7. La Olla Común: una etnografía arquitectónica. The Common Pot: an architectural ethnography. Abásolo-Llaría, José.

8. Taller vertical, diseño de hábitat resiliente indígena: experiencia docente conectada. Vertical workshop, indigenous resilient habitat design: connected teaching experience. Lobato-Valdespino, Juan Carlos; Flores-Romero, Jorge Humberto.

9. Lecciones espaciales de las instalaciones artísticas. Learning from the space in art installations. Zaparaín-Hernández, Fernando; Blanco-Martín, Javier.

10. Alternativas para enseñar arquitectura: del proyecto introspectivo al campo expandido. Alternatives for Teaching Architecture: From the Introspective Project to the Expanded Field. Juarranz Serrano, Angela; Rivera Linares, Javier.

11. Una Herramienta de apoyo a la Docencia de las Matemáticas en los Estudios de Arquitectura. A Tool to support the Teaching of Mathematics for the Degree in Architectura. Reyes-Iglesias, María Encarnación.

12. Luvina, Juan Rulfo: materia de proyecto. Luvina, Juan Rulfo: matter of project. Muñoz-Rodríguez, Rubén; Pastorelli-Paredes, Giuliano. 
13. No se trata de ver videos: métodos de aprendizaje de la geometría descriptiva. It's not about watching videos: descriptive geometry learning methods. Álvarez Atarés, Fco. Javier.

14. Integration of Art-Based Research in Design Curricula. Integración de investigación basada en el arte en programas de diseño. Paez, Roger; Valtchanova, Manuela.

15. ¿Autómatas o autónomas? Juegos emocionales para el empoderamiento alineado y no alienado. Automata or autonomous? Emotional games for aligned and non-alienated empowerment. Ruiz Plaza, Angela.

16. Otras agendas para el estudiante. Another student agendas. Minguito-García, Ana Patricia.

17. Los Archivos de Arquitectura: una herramienta para la docencia con perspectiva de género. The Archives of Architecture: a tool for teaching with a gender perspective. Ocerin-Ibáñez, Olatz; Rodríguez-Oyarbide, Itziar.

18. Habitar 3.0: una estrategia para (re)pensar la arquitectura. Inhabiting 3.0: a strategy to (re)think architecture. González-Ortiz, Juan Carlos.

19. Actividades de aprendizaje para sesiones prácticas sobre la construcción en arquitectura. Learning activities for practical sessions about construction in architecture. Pons-Valladares, Oriol.

20. Getaria 2020: inspirar, pintar, iluminar. Getaria 2020: inspire, paint, enlight. Mujika-Urteaga, Marte; Casado-Rezola, Amaia; Izkeaga-Zinkunegi, Jose Ramon.

21. Aprendiendo a vivir con los otros a través del diseño: otras conversaciones y metodologías. Learning to live with others through design: other conversations and methodologies. Barrientos-Díaz, Macarena; Nieto-Fernández, Enrique.

22. Geogebra para la enseñanza de la Geometría Descriptiva: aplicación para la docencia online. Geogebra for the teaching of Descriptive Geometry: application for online education. Quintilla Castán, Marta; Fernández-Morales, Angélica.

23. La crítica bypass: un taller experimental virtual. The bypass critic: a virtual experimental workshop. Barros-Di Giammarino, Fabián.

24. Urbanismo táctico como herramienta docente para transitar hacia una ciudad cuidadora. Tactical urbanism as a teaching tool for moving towards a caring city. Telleria-Andueza, Koldo; Otamendi-Irizar, Irati.

25. Proyectos orales. Oral projects. Cantero-Vinuesa, Antonio.

26. Intercambios docentes online: una experiencia transdisciplinar sobre creación espacial. Online teaching exchanges: a transdisciplinary experience on spatial creation. Llamazares Blanco, Pablo. 
27. Nuevos retos docentes en geometría a través de la cestería. New teaching challenges in geometry through basketry. Casado-Rezola, Amaia; SanchezParandiet, Antonio; Leon-Cascante, Iñigo.

28. Mecanismos de evaluación a distancia para asignaturas gráficas en Arquitectura. Remote evaluation mechanisms for graphic subjects in architecture. Mestre-Martí, María; Muñoz-Mora, Maria José; Jiménez-Vicario, Pedro M.

29. El proceso didáctico en arquitectura es un problema perverso: la respuesta, un algoritmo. The architectural teaching process is a wicked problema: the answer, an algorithm. Santalla-Blanco, Luis Manuel.

30. La experiencia de habitar de los estudiantes de nuevo ingreso: un recurso docente. The experience of inhabiting in new students: a teaching resource. Vicente-Gilabert, Cristina; López Sánchez, Marina.

31. Habitar la Post·Pandemia: una experiencia docente. Inhabiting the Post-Pandemic: a teaching experience. Rivera-Linares, Javier; Ábalos-Ramos, Ana; Domingo-Calabuig, Débora; Lizondo-Sevilla, Laura.

32. El arquitecto ciego: método Daumal para estudiar el paisaje sonoro en la arquitectura. The blind architect: Daumal method to study the soundscape in architecture. Daumal-Domènech, Francesc.

33. Reflexión guiada como preparación previa a la docencia de instalaciones en Arquitectura. Guided reflection in preparation for the teaching of facilities in Architecture. Aguilar-Carrasco, María Teresa; López-Lovillo, Remedios María.

34. PhD: Grasping Knowledge Through Design Speculation. PhD: acceder al conocimiento a través de la especulación proyectual. Bajet, Pau.

35. andamiARTE: la Arquitectura Efímera como herramienta pedagógica. ScaffoldART: ephemeral Architecture as a pedagogical tool. Martínez-Domingo, Yolanda; Blanco-Martín, Javier.

36. Como integrar la creación de una biblioteca de materiales en la docencia. How to integrate the creation of a materials library into teaching. Azcona-Uribe, Leire.

37. Acciones. Actions. Gamarra-Sampén, Agustin; Perleche-Amaya, José Luis.

38. Implementación de la Metodología BIM en el Grado en Fundamentos de Arquitectura. Implementation of BIM Methodology in Bachelor's Degree in Architecture. Leon-Cascante, Iñigo; Uranga-Santamaria, Eneko Jokin; RodriguezOyarbide, Itziar; Alberdi-Sarraoa, Aniceto.

39. Cartografía de Controversias como recurso para analizar el espacio habitado. Mapping Controversies as a resourse for analysing the inhabited space. EspañaNaveira, Paloma; Morales-Soler, Eva; Blanco-López, Ángel. 
40. Percepciones sobre la creatividad en el Grado de Arquitectura. Perceptions on creativity at the Architecture Degree. Bertol-Gros, Ana; López, David.

41. El paisajismo en la redefinición del espacio público en el barrio de San Blas, Madrid. The landscape architecture in the redefinition of public space in the neighbourhood of San Blas, Madrid. Del Pozo, Cristina; Jeschke, Anna Laura.

42. De las formas a los flujos: aproximación a un proyecto urbano [eco]sistémico. Drawing throught a screen: teaching architecture in a digital world. CrosasArmengol, Carles; Perea-Solano, Jorge; Martí-Elias, Joan.

43. Dibujar a través de una pantalla: la enseñanza de la arquitectura en un mundo digital. Drawing throught a screen: teaching architecture in a digital world. Alonso-Rodríguez, Marta; Álvarez-Arce, Raquel.

44. Land Arch: el arte de la tierra como Arquitectura, la Arquitectura como arte de la tierra. Land Arch: Land Art as Architecture, Architecture as Land Art. ÁlvarezAgea, Alberto; Pérez-de la Cruz, Elisa.

45. Hyper-connected hybrid educational models for distributed learning through prototyping. Modelo educacional híbrido hiperconectado para el aprendizaje mediante creación de prototipos. Chamorro, Eduardo; Chadha, Kunaljit.

46. Ideograma. Ideogram. Rodríguez-Andrés, Jairo; de los Ojos-Moral, Jesús; FernándezCatalina, Manuel.

47. Taller de las Ideas. Ideas Workshop. De los Ojos-Moral, Jesús; Rodríguez-Andrés, Jairo; Fernández-Catalina, Manuel.

48. Los proyectos colaborativos como estrategia docente. Collaborative projects as a teaching strategy. Vodanovic-Undurraga, Drago; Fonseca-Alvarado, MaritzaCarolina; Noguera- Errazuriz, Cristóbal; Bustamante-Bustamante, Teresita-Paz.

49. Paisajes Encontrados: docencia remota y pedagogías experimentales confinadas. Found Landscapes: remote teaching and experimental confined pedagogies. Prado Díaz, Alberto.

50. Urbanismo participativo: una herramienta docente para tiempos de incertidumbre. Participatory urban planning: a teaching tool for uncertain times. Carrasco i Bonet, Marta; Fava, Nadia.

51. El portafolio como estrategia para facilitar el aprendizaje significativo en Urbanismo. Portfolio as a strategy for promoting meaningful learning in Urbanism. Márquez-Ballesteros, María José; Nebot-Gómez de Salazar, Nuria; Chamizo-Nieto, Francisco José.

52. Participación activa del estudiante: gamificación y creatividad como estrategias docentes. Active student participation: gamification and creativity as teaching strategies. Loren-Méndez, Mar; Pinzón-Ayala, Daniel; Alonso-Jiménez, Roberto F. 


\section{JIDA}

53. Cuaderno de empatía: una buena práctica para conocer al usuario desde el inicio del proyecto. Empathy workbook - a practice to better understand the user from the beginning of the project. Cabrero-Olmos, Raquel.

54. Craft-based methods for robotic fabrication: a shift in Architectural Education. Métodos artesanales en la fabricación robótica: una evolución en la experiencia docente. Mayor-Luque, Ricardo; Dubor, Alexandre; Marengo, Mathilde.

55. Punto de encuentro interdisciplinar: el Museo Universitario de la Universidad de Navarra. Interdisciplinary meeting point. The University Museum of the University of Navarra. Tabera Roldán, Andrés; Velasco Pérez, Álvaro; Alonso Pedrero, Fernando.

56. Arquitectura e ingeniería: una visión paralela de la obra arquitectónica. Architecture and engineering: a parallel vision of architectural work. GarcíaAsenjo Llana, David.

57. Imaginarios Estudiantiles de Barrio Universitario. Student's University Neighborhood Imaginaries. Araneda-Gutiérrez, Claudio; Burdiles-Allende, Roberto; Morales-Rebolledo Dehany.

58. El aprendizaje del hábitat colectivo a través del seguimiento del camino del refugiado. Learning the collective habitat following the refugee path. CastellanoPulido, F. Javier.

59. El laboratorio de investigación como forma de enseñanza: un caso de aprendizaje recíproco. The research lab as a form of teaching: a case of reciprocal learning. Fracalossi, Igor. 


\title{
Otras agendas para el estudiante Another student agendas
}

\author{
Minguito-García, Ana Patricia \\ Escuela Técnica Superior de Arquitectura, Universidad Politécnica de Madrid, España. \\ ap.minguito@gmail.com
}

\begin{abstract}
Nowadays, architecture has extended its area of influence to an interdisciplinary context, that is much broader than the purely building one. Therefore, it is important to question the professional framework that is transmitted to the student from the teaching perspective, proposing a pedagogical alternative that encourages students to rethink the essence of his/her identity in the field professional context. Results extracted from the application of a teaching methodology based on a professional agenda research, in a postgraduate seminar at a Spanish School of Architecture, state that the architect role most shared by students requires a much more interdisciplinary and, at the same time, limited framework of action. Raising, as a conclusion of the communication, the need to introduce a renewed teaching approach to the profession, taking into consideration the present demand of students for a more detailed professional orientation.
\end{abstract}

Keywords: agenda, role of the architect, transdisciplinarity, teaching perspective, student identity.

Thematic areas: pedadogy, self-regulated learning, educational research.

\section{Resumen}

Hoy en día la arquitectura ha extendido su área de influencia a un contexto interdisciplinar mucho más amplio que el puramente edificatorio. Por lo que resulta importante poner en crisis el encuadre profesional que se trasmite al estudiante desde la perspectiva docente, proponiendo una alternativa pedagógica que incite al mismo a replantearse su esencia de identidad de cara al contexto profesional del campo. Los resultados extraídos de la aplicación de una metodología docente —de búsqueda de una agenda profesional-, en un seminario de posgrado de una Escuela de Arquitectura española, sentencian que el rol del arquitecto más compartido por los estudiantes requiere un marco de actuación mucho más interdisciplinar y, a la vez, más acotado. Planteando, como conclusión de la comunicación, la necesidad de introducir un renovado enfoque docente de la profesión, teniendo en consideración la palpable demanda del estudiante de una orientación profesional más pormenorizada.

Palabras clave: agenda, rol del arquitecto, transdisciplinariedad, perspectiva docente, identidad del estudiante.

Bloques temáticos: pedagogía, metodologías de autorregulación del aprendizaje, investigación educativa. 


\section{Introducción}

La agenda profesional del campo arquitectónico por antonomasia ha sido siempre ejercer la profesión desde los principios del diseñar, construir y firmar proyectos (ya fuesen viviendas unifamiliares, VPO, bibliotecas, hospitales, centros comerciales o pequeñas construcciones; lo que estuviera al alcance del mercado laboral). Sin embargo, actualmente la arquitectura como disciplina ha extendido su área de influencia a un contexto multidisciplinar mucho mayor que el puramente edificatorio. El desarrollo de actividades que se encuentran fuertemente vinculadas a la profesión pero que, no obstante, se alejan al mismo tiempo sustancialmente de esa necesidad inculcada del construir, es lo que precisamente está representando el papel divulgativo actual de la profesión, rompiendo el hermético tabú forjado en torno a la figura tradicional del arquitecto/a (Montaner, 2015).

Por ello, resulta meramente importante cuestionar si, a día de hoy, es necesaria la existencia explícita de una asignatura práctica en la formación académica del estudiante, que incite al mismo replantearse su esencia de identidad de cara al contexto profesional del campo. Y que le proporcione, además, los conocimientos útiles imprescindibles para poder sacar adelante una oficina el día de mañana, sea cual sea el enfoque profesional de la misma -0 , al menos, desarrollar de forma más fructífera sus competencias laborales, en cualquier empresa del sector o ajena a él en el que fuera empleado-.

\section{El seminario como punto de partida. [Objetivos]}

La presente comunicación busca abordar y poner en crisis el encuadre profesional que se trasmite al estudiante desde el análisis de la experiencia recogida en un seminario de posgrado de una Escuela de Arquitectura española, orientado precisamente a la búsqueda por parte del estudiante de su imagen profesional de identidad.

El objetivo principal de la tesis de estudio reside en incitar al estudiante a determinar cuál es su rol de arquitecto/a dentro del panorama profesional actual. Para ello, se introduce el concepto pedagógico de "agenda profesional" con el propósito de ayudar al estudiante a establecer las directrices de identidad de su propia figura dentro de la profesión.

El objeto final de la investigación es lograr que el estudiante clarifique de manera concisa sus intereses y objetivos profesionales, antes de abandonar el campo académico y ser arrojado a un mercado laboral con escasa o nula experiencia previa (Luque, 2020).

\section{Experiencias de contextualización. [Marco teórico]}

El texto se enmarca dentro de una experiencia propia basada en una larga trayectoria de cursos impartidos, donde los contenidos docentes transmitidos se han ido amoldando año tras año para dar forma al seminario objeto de la comunicación.

La experiencia docente desarrollada se vincula, dentro de un marco teórico acotado, a otras experiencias históricas que sirven de referencia para la aplicación de cualquier metodología de nueva implantación. La conocida Bauhaus ${ }^{1}$ (Gropius, 1966) y su método de enseñanza de la

\footnotetext{
1 Escuela de arquitectura, diseño, artesanía y arte fundada en 1919 por Walter Gropius en Weimar (Alemania). Sus propuestas y declaraciones de intenciones participaban de la idea de una necesaria reforma de las enseñanzas artísticas como base para una consiguiente transformación de la sociedad burguesa de la época, de acuerdo con el pensamiento socialista de su fundador.
} 
arquitectura como habilitación para la práctica profesional ${ }^{2}$ (Wick, 1993) (Fig. 1), sirve ahora de referente para su actualización a los debates pedagógicos contemporáneos. Del mismo modo que la arquitectura radical de los años setenta, la cual proponía superar los límites de una arquitectura formalista a una renovada a los intereses de la sociedad ${ }^{3}$ (Rotman, 2014). Dicha mediación entre el mundo de las ideas y la práctica profesional es la perseguida en la metodología de aplicación que protagoniza esta comunicación: sin relegar a un segundo plano la teoría o fase de ensoñación, ${ }^{4}$ no olvidar el componente práctico que caracteriza a toda arquitectura.

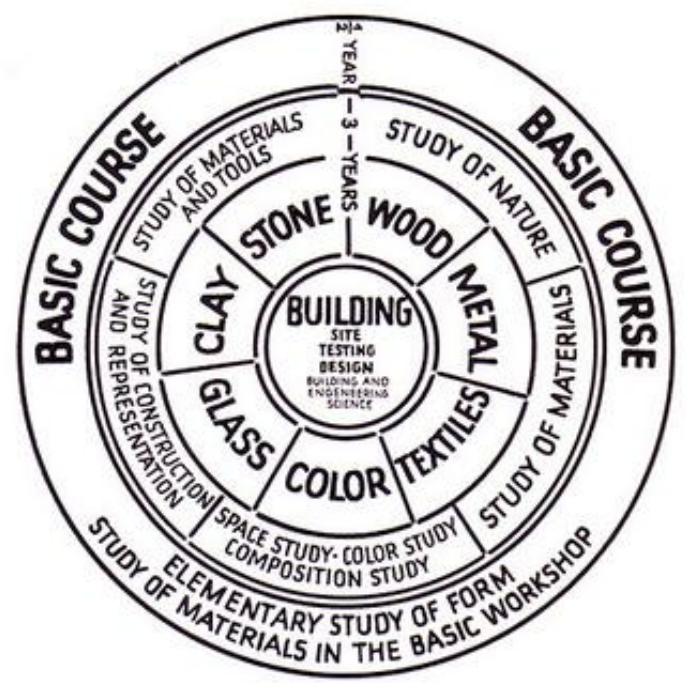

Fig. 1 Diagrama del programa educativo de la Bauhaus, 1921. Fuente: Wick, R (1993)

La investigación se apoya, además, en experiencias relatadas en ediciones anteriores del congreso JIDA relacionadas con diversos perfiles profesionales, que continúan la línea de aplicación de estructuras de comunicación y trabajo dinámicos, e incorporan el concepto de "taller" en la docencia de arquitectura con el objetivo de lograr fomentar entornos de aprendizaje más participativos y de empoderamiento (Masdéu, 2018).

\section{La base pedagógica de la experiencia. [Contenidos docentes]}

Los contenidos docentes trabajados se fundamentan en la base pedagógica del discurso establecida bajo conceptos tales como identidad, declaración de intenciones, imagen de marca, agenda, oficina o ideograma, entre otros (Lázaro, 2019). La experiencia asienta su pedagogía

\footnotetext{
${ }^{2}$ Era una de las muchas posibilidades de las artesanías que allí se enseñaban, donde resultaba importante inculcar un carácter práctico de aplicación a los conocimientos teóricos inculcados. De ahí que el carácter simplista y funcional de los diseños adquiriera protagonismo en los resultados de las pedagogías llevadas a cabo, pero sin olvidar que medios auxiliares como la imagen plástica o la fotografía publicitaria resultaban fundamentales para potenciar la difusión de una geometría básica de materiales homogéneos.

${ }^{3}$ La arquitectura de los años setenta buscaba flexibilizar los límites disciplinares mediante potentes imágenes de transgresión del mundo existente a uno puramente utópico mecanicista, sin dejar de lado el arraigo cultural de las propuestas y desarrollando un plausible interés por la evolución de los materiales o las posibilidades que otorgaba la tecnología en aquel momento.

${ }^{4}$ Suceso, proyecto, aspiración o cosa que se anhela o se persigue pese a ser muy improbable que se realice y en el que se piensa con placer. En referencia a la comúnmente denominada como "fase de idea".
} 
en la puesta en práctica, de forma concisa y pormenorizada, de cuatro de esos conceptos clave: identidad, "statement", imagen y agenda.

\subsection{Identidad: la cabeza de cadena}

El significado de "identidad" es el punto de partida para la creación de una cadena de relaciones que da lugar a un mecanismo conceptual. Las acepciones dos y tres de la RAE detallan con exactitud qué se quiere transmitir al estudiante al poner en práctica dicho concepto ${ }^{5}$ (RAE, 2020). No solo se trata de que sea capaz de tener conciencia del rol profesional al que está enfocando o pretende enfocar su aprendizaje, sino también de que adquiera la habilidad de discernir cuál es el conjunto de rasgos propios que caracterizan a dicha vertiente vocacional. Esto hace que se despierten una u otra serie de inquietudes que condicionan indiscutiblemente la orientación profesional de cada estudiante. $^{6}$

Ambos términos de arquitectura e identidad tienden a utilizarse simultáneamente como un par de conceptos frecuentemente relacionados ${ }^{7}$ (Piñón, 2006). Es más, esta relación de dependencia se intensifica a medida que se incrementa la contemporánea necesidad de conocimiento de las nuevas generaciones en aspectos temáticos no convencionales -al menos en lo que a tradición arquitectónica se refiere-. Las actuales vertientes de trabajo relacionadas con el campo son las que demandan una mayor noción de permanencia y solidez en la relación de unidad con la cultura social en la que se inserta cada experiencia de trabajo arquitectónico (Solà-Morales, 2000).

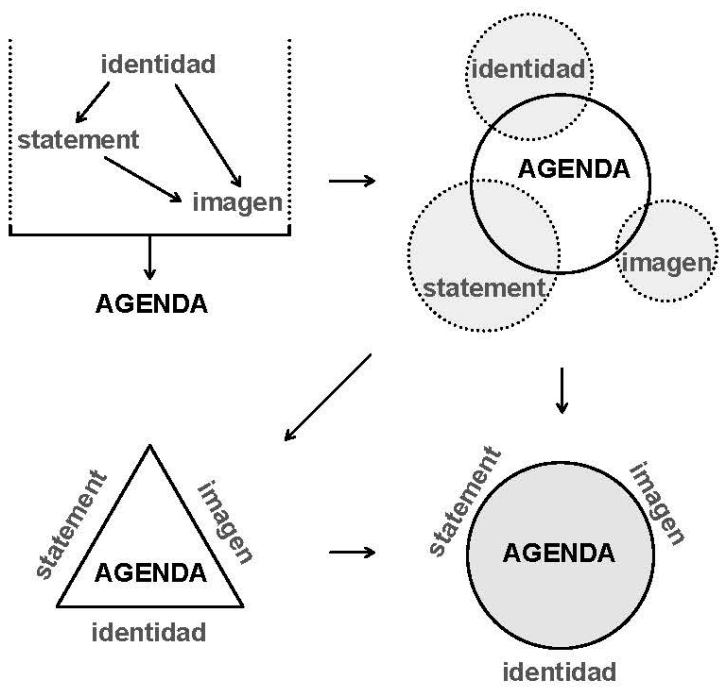

Fig. 2 Evolución del diagrama relacional de conceptos. Fuente: Minguito, A.P. (2021) —elaboración propia-

\footnotetext{
${ }^{5}$ Acepciones dos y tres del diccionario de la Real Academia Española: conjunto de rasgos propios de un individuo o de una colectividad que los caracterizan frente a los demás; conciencia que una persona o colectividad tiene de ser ella misma y distinta a las demás.

${ }^{6}$ La identidad se entiende como un término proveniente del vocablo latino "idem" y simplemente puede comenzar por interpretase como "Io mismo". En filosofía, es observada como "la persistencia del ser" ante cualquier cambio, y en psicología como "la conciencia del yo"; como un principio de identidad enfocado en el ser, en el conocimiento y en la corporeidad; esto es, como un fiel reflejo de los intereses que persisten y permanecen invariables en el desarrollo académico de cada estudiante.

7 La

a arquitectura es susceptible de interpretarse como la depositaria directa e indirecta de la identidad no solo del proyectista o del usuario, sino de la memoria que se genera en torno a su desarrollo o contextualización. Es aquí donde el concepto de identidad se establece como un agente definitorio, en la medida que interpreta un ente arquitectónico a través de atributos tangibles e intangibles.
} 


\section{2. "Statement": enunciando una declaración de intenciones}

Como en cualquier otro proceso de transferencia, el resto de conceptos base no se sitúan al mismo nivel. Bien es verdad que la condición de relación de dependencia entre ellos es indiscutible - tal y como se representa en el gráfico (Fig. 2)-, pero han de introducirse en el discurso pedagógico de una manera secuencial y no simultánea.

El concepto de "statement" ocupa el segundo lugar en la línea relacional, al encontrarse directamente vinculado con el primer término trabajado. Se permite la utilización del anglicismo porque reúne en su constitución las acepciones de declaración, exposición y argumentación de un conjunto de hechos (Collins, 2005). Precisamente, es esa combinación de tres acciones lo que ayuda al estudiante a definir el campo identitario al que enfocar su interés profesional.

El "statement" alude al desarrollo de una práctica arquitectónica que apela al emprendimiento de una nueva perspectiva profesional alternativa ${ }^{8}$ (Aguirre, 2015). Para hacer frente a dicho dilema, es necesario incitar a las futuras y presentes generaciones a tomar una mínima distancia crítica que fisure ese anclaje al pasado, ante una demanda de alternativos roles arquitectónicos que se presenta irreversible. ${ }^{9}$ Es decir, reconstruir el papel del arquitecto como productor $-\mathrm{y}$ no como constructor- en el campo arquitectónico (Carretero, 2016).

Por lo tanto, resulta fundamental no sólo que el estudiante sea capaz de determinar el interés al que enfocar su formación profesional, sino que igualmente sea consciente de lo que ello implica. De ahí la importancia de elaborar una lista de enunciados que completen un "statement" que sea resultado de esa definición de identidad inicial.

\subsection{Imagen: una entidad resultado de palabras}

La combinación de los diferentes enunciados propicia la aparición de una "imagen de marca" de cada agenda. No basta con que el estudiante sepa identificar y definir las características que definen su rol de arquitecto, sino que ha de poder transmitirlas de manera convincente; esto es, vender un modelo posible de práctica profesional.

Debido a que esta experiencia docente fomenta la concienciación del estudiante en torno a la creación de nuevos roles posibles en el campo de la arquitectura, no debe definirse únicamente de forma teórica, sino que ha de impulsarse su aplicación a un contexto verídico y real. Para ello, debe tenerse en cuenta no sólo el campo al que va destinado el rol definido - ya sea de nueva índole o más cercano al puramente tradicional—, sino también a qué público se destina y por qué público puede ser customizado. ${ }^{10}$

\footnotetext{
8 Ante la "inevitable" desaparición de la práctica tradicional como "Estado de Bienestar" ya consumado, el "statement" no opera tan solo a nivel técnico, sino que lo hace también en un sustrato práctico, señalando las infraestructuras materiales y organizativas que el sistema demanda para las nuevas generaciones de arquitectos, así como los objetivos económicos y la implantación social a perseguir. Se trata, pues, de interpretar un enunciado — siguiendo la máxima nietzscheana "no hay hechos sin interpretaciones"— que es tan arquitectónico como ideológico. Una visión neoliberal de la práctica arquitectónica por venir que alienta a actuar: ante la desaparición inevitable del "Estado de Bienestar" debemos emprender.

${ }^{9}$ Las resistencias crecientes, tanto a nivel global como local, que encuentra la praxis de una arquitectura comprometida —esto es, para con su propia disciplina y sociedad mediante un ejercicio mayoritariamente práctico y no tanto auto-reflexivo e intelectual-, representan síntomas a su vez de la dificultad para establecer una alternativa a lo ya conocido y exprimido a máxima demanda, dentro de la cotidiana burbuja del construir.

10 Esta conexión entre el mundo de las ideas y la práctica profesional resulta bastante pertinente llevarla a cabo para que verdaderamente la experiencia docente no se quede en otro baúl de contenido teórico enunciado, sino que pueda aplicarse de forma realista una vez que el estudiante finalice su formación y se lance al mundo laboral.
} 
Definir la identidad del rol arquitectónico interesado, enunciar los establecimientos del "statement", e identificar la imagen de marca asociada, desemboca en la determinación de la agenda profesional como concepto global.

\subsection{Agenda: un concepto unificador}

Según la experiencia llevada a cabo, el concepto de "agenda" resulta bastante complejo de transmitir al estudiantado. No obstante, si se enfoca desde el sentido de "relación", y se incluye el significado asociado al anglicismo, se esclarece la definición: la palabra agenda pone en consonancia de manera ordenada el conjunto de hechos, intenciones y motivaciones desarrolladas en el "statement", a fin de organizarlas y establecer un orden aparente de correspondencia entre todas ellas. Manteniendo como referente la "identidad" definida y la "imagen" representacional elaborada, se engloba la experiencia bajo un solo concepto que condensa lo anterior.

Por lo que, solo abordando de manera conjunta tanto la aproximación conceptual como la puesta en práctica real $-\mathrm{y}$ ambas desde el punto de vista del interés de cada estudiante-, se definen los nuevos roles que caracterizan a las agendas alternativas que demanda la arquitectura a día de hoy.

Es preciso mencionar que el calificativo arquitectónico se utiliza en la definición de la presente base pedagógica como atributo a modo de ejemplificación del método puesto en práctica. Esto determina, por tanto, que dicha base pedagógica es igualmente aplicable en la misma secuencia descrita a otras disciplinas similares al campo de la arquitectura, o incluso -aportando un carácter más transdisciplinar-ajenas al mismo.

\section{Dos fases, una metodología de aplicación. [Método]}

La investigación se aplica en un seminario optativo de un curso de posgrado que permite crear un grupo de trabajo reducido y bastante heterogéneo, en el que cada estudiante es partícipe del trabajo y evolución del otro. ${ }^{11}$

No obstante, es preciso tener en cuenta que, al tratarse de una experiencia docente con una participación bastante reducida de estudiantes, resulta difícil extraer unas conclusiones demasiado categóricas respecto a la docencia en arquitectura que puedan ser determinantes. Precisamente por ello, se considera más enriquecedor detallar de forma pragmática y concisa la metodología experimentada (apuntando hallazgos relevantes, así como posibles puntos de mejora para posteriores ediciones del seminario —o para otros casos de aplicación en diferentes escuelas españoles o contextos multidisciplinares-), y que esto se convierta en el objeto central de la comunicación.

Dicha metodología se configura a partir de la confrontación de dos fases de aplicación secuenciales. ${ }^{12}$

\footnotetext{
${ }^{11}$ En el curso realizado, el grupo de trabajo se compone de un total de quince estudiantes y dos profesores, contando, además, con gran heterogeneidad cultural al tratarse de un taller de investigación de interés internacional (un total de seis nacionalidades distintas aportan nuevos enfoques, dinámicas y diversidad de intereses y objetivos).

12 El seminario tiene una duración de un curso académico (misma duración que la del propio posgrado), por lo que cada una de las fases se divide según dos cuatrimestres: la fase uno se desarrolla durante el cuatrimestre de otoño, y la fase dos durante el de primavera. El seminario se imparte con una sesión semanal de dos horas de duración — tanto para el trabajo individual/grupal de los estudiantes como para las sesiones de debate- Es preciso mencionar que, en la medida de lo posible, sería preferible realizarlo de forma intensiva: esto
} 


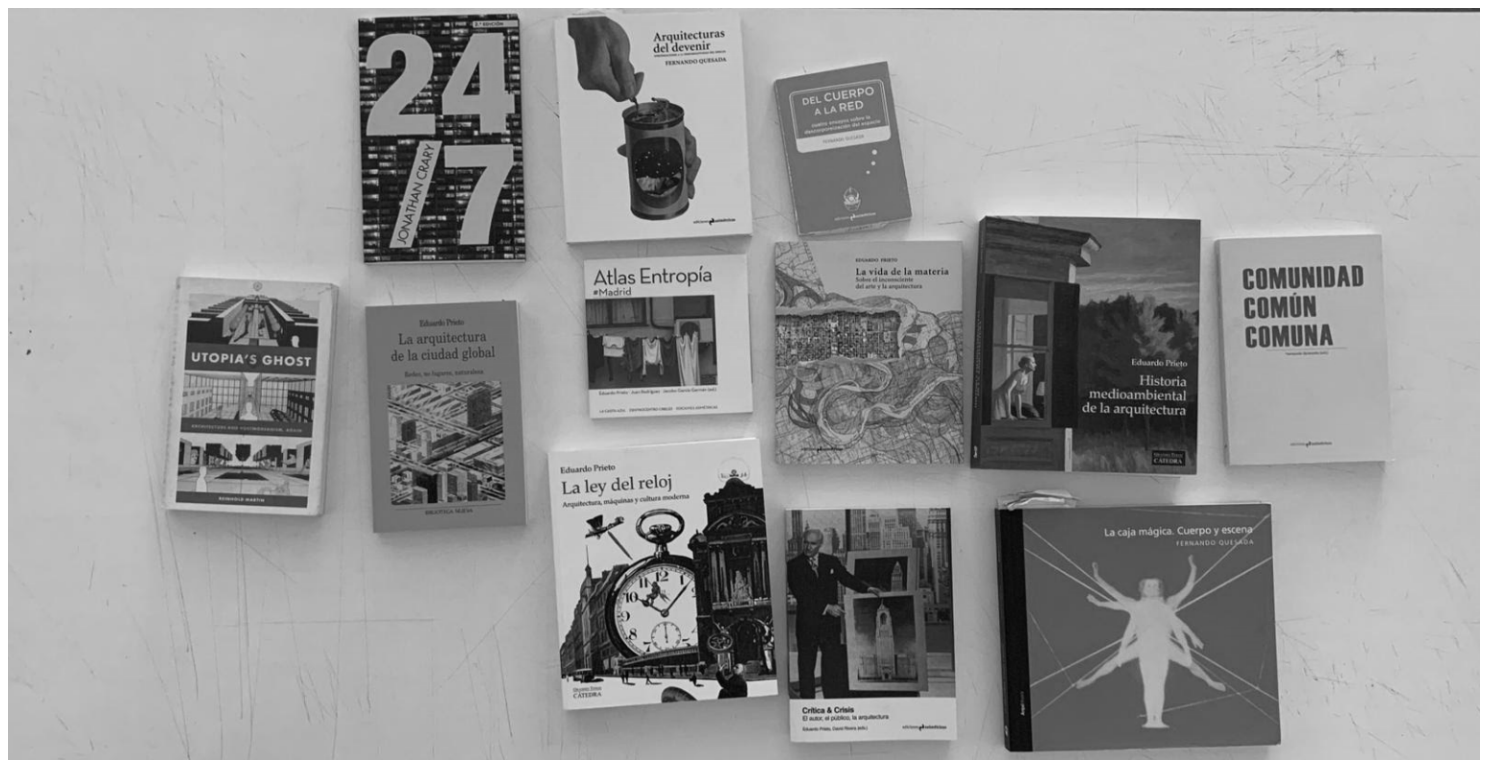

Fig. 3 Imagen de las referencias bibliográficas utilizadas por los estudiantes para llevar a cabo la definición de las distintas agendas. Fuente: Minguito, A.P. (2021)—elaboración propia-

\subsection{Fase "teoría"}

La primera fase de aplicación concierne al desarrollo teórico de la metodología: transmitidos los conceptos fundamentales (Fig. 3), el estudiante debe abordar la definición de la agenda a través de la identificación de su esencia de identidad.

El propio estudiante se convierte en un instrumento más de la operación, al incorporar la posibilidad de decisión de la forma en la que actuar para sacar adelante la agenda: bien de manera individual o bien mediante la asociación con otros estudiantes del seminario. Permitir al estudiante definir la esencia de su propia agenda de forma individual, dota al mismo de la adquisición de una gran autonomía en la toma de decisiones, pero recrea un acercamiento más utópico al campo real de la profesión. Por el contrario, fomentar la asociación en pequeños grupos de estudiantes donde resulta indiscutible la puesta en práctica de diálogo y consenso, se asemeja más a la realidad cotidiana de trabajo en una oficina (Martin, 2005) —con mayor riqueza y heterogeneidad-. ${ }^{13}$

Tras la sesión de debate y puesta en marcha de asociaciones entre los estudiantes del seminario, se concretan un total de ocho agendas: tres individuales, cuatro dúos y un grupo de cuatro integrantes. Cada agenda es definida por los estudiantes (sin intercesión del profesorado) teniendo en cuenta los contenidos docentes transmitidos: se determina en cada caso un nombre de marca que refleje de forma directa la esencia de la agenda, y unos principios base que establezcan el "statement" que da lugar a la definición de la imagen de cada agenda —la cual es presentada a través de una vía comunicativa pública de exposición (sitio web, Instagram, YouTube, etc)-.

es, condensándolo en un solo cuatrimestre. Así, se llevaría a cabo un cambio en la concepción del seminario teórico-práctico hacia un enfoque de taller-workshop permanente, donde el trabajo, diálogo y sesión crítica pudieran realizarse simultáneamente.

13 Hay que tener en cuenta que paralelamente se inculca un aprendizaje trasversal: mientras que la actuación individual permite al estudiante desarrollar su propio interés de agenda profesional, también le desvela la complicaciones y mayor carga de trabajo para sacar adelante la propuesta profesional que conlleva una actuación por separado; por el contrario, un trabajo en equipo permite sacar adelante de forma más eficaz — aunque no necesariamente con mejores resultados- el desarrollo de la agenda profesional, pero también conlleva al estudiante a supeditar los intereses propios a favor del resultado de la propuesta global. 


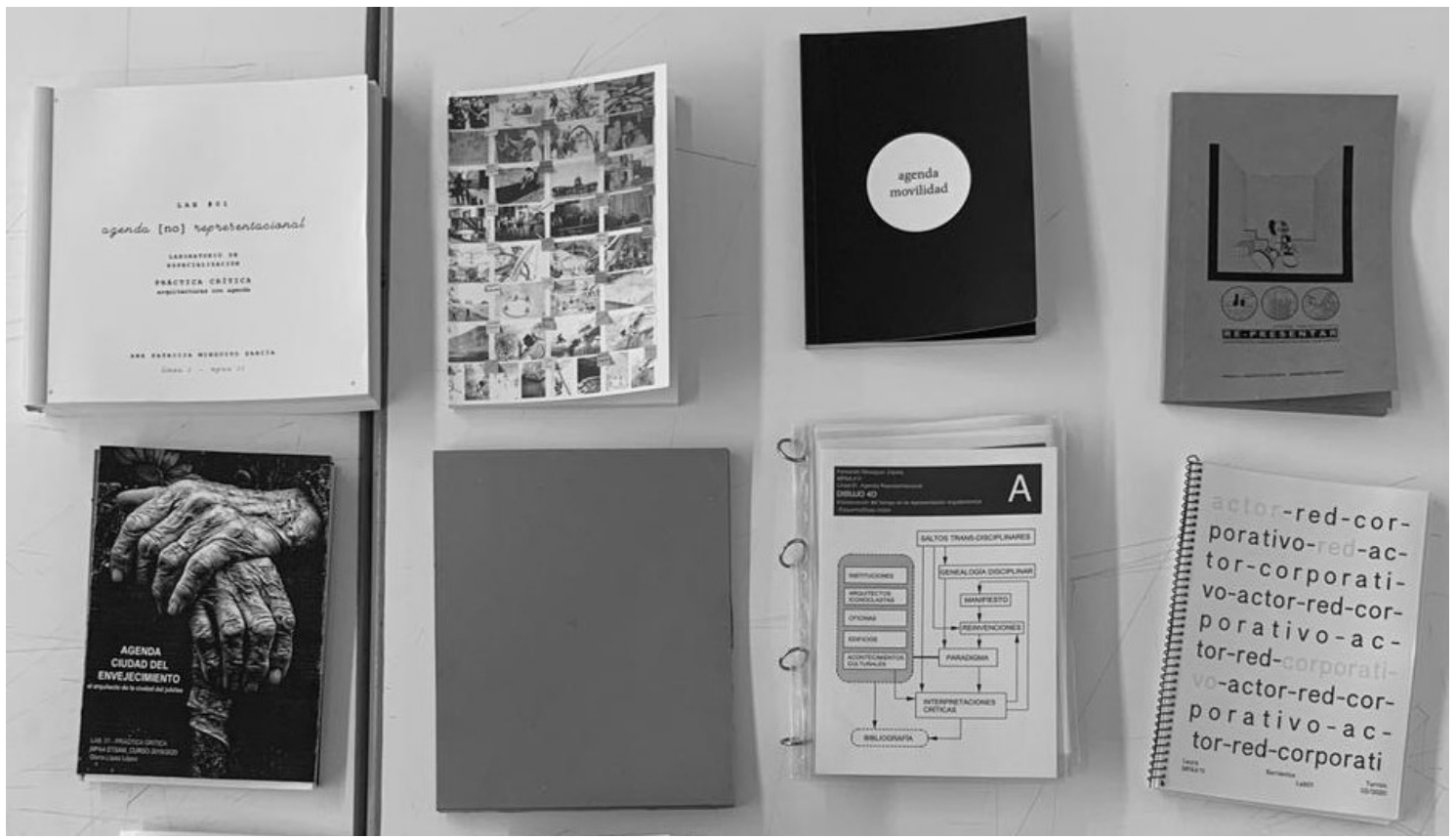

Fig. 4 Imagen de los portfolios realizados por el estudiante/grupo de las referencias basadas en proyectos de oficinas con agendas similares a la definida por cada uno. Fuente: Minguito, A.P. (2021) —elaboración propia-

Como soporte de ayuda a la definición de cada elemento, se incita a cada estudiante/grupo a realizar una recopilación —a modo de monografía-portfolio (Fig. 4)— de referencias basadas en proyectos de oficinas con agendas similares, que actualmente ejercen su profesión en el mundo laboral. Por último, se deja a libre elección del estudiante/grupo la utilización de uno u otro instrumento-formato de presentación de la propuesta en la sesión de cierre de la fase teórica: papel, digital o mixta, según mejor se adecúe a la demanda actual del mercado en el que se involucre cada agenda.

El profesorado orienta a cada estudiante/grupo sobre los aspectos a clarificar de cada agenda, aportando referencias de otras oficinas, estudios, empresas o asociaciones, según sea necesario profundizar en uno u otro aspecto trabajado. ${ }^{14}$ Además, se valora cada ejemplo de referencia seleccionado, cuestionando al estudiante sobre la elección, y animándole a elaborar un hilo discursivo que enlace todos los aspectos y material trabajado, para establecer una jerarquía entre conceptos e ideas que descarte aquello que desvíe a la agenda de su definición original.

Siguiendo la línea de investigación de otras comunicaciones presentadas al congreso en ediciones anteriores, se analizan y comparten las estrategias desarrolladas en sesiones de valoración intermedia y final (Fig. 5 y 6), para motivar al estudiante a involucrarse en la metodología del propio seminario: participando en el aula y compartiendo con sus compañeros su propio punto de vista de la experiencia realizada. A través del alcance de las competencias previstas en la metodología docente, el objetivo final es motivar al estudiante de posgrado a que sea responsable de su propio aprendizaje en experiencias venideras (Guardiola, Pérez, 2017).

\footnotetext{
${ }^{14}$ Ya sea mejorar el enunciado del eslogan o palabra que sintetiza la identidad de la agenda, el redactado de los principios básicos del "statement", o la incorporación de otras imágenes que representen la esencia de cada agenda con más rotundidad.
} 


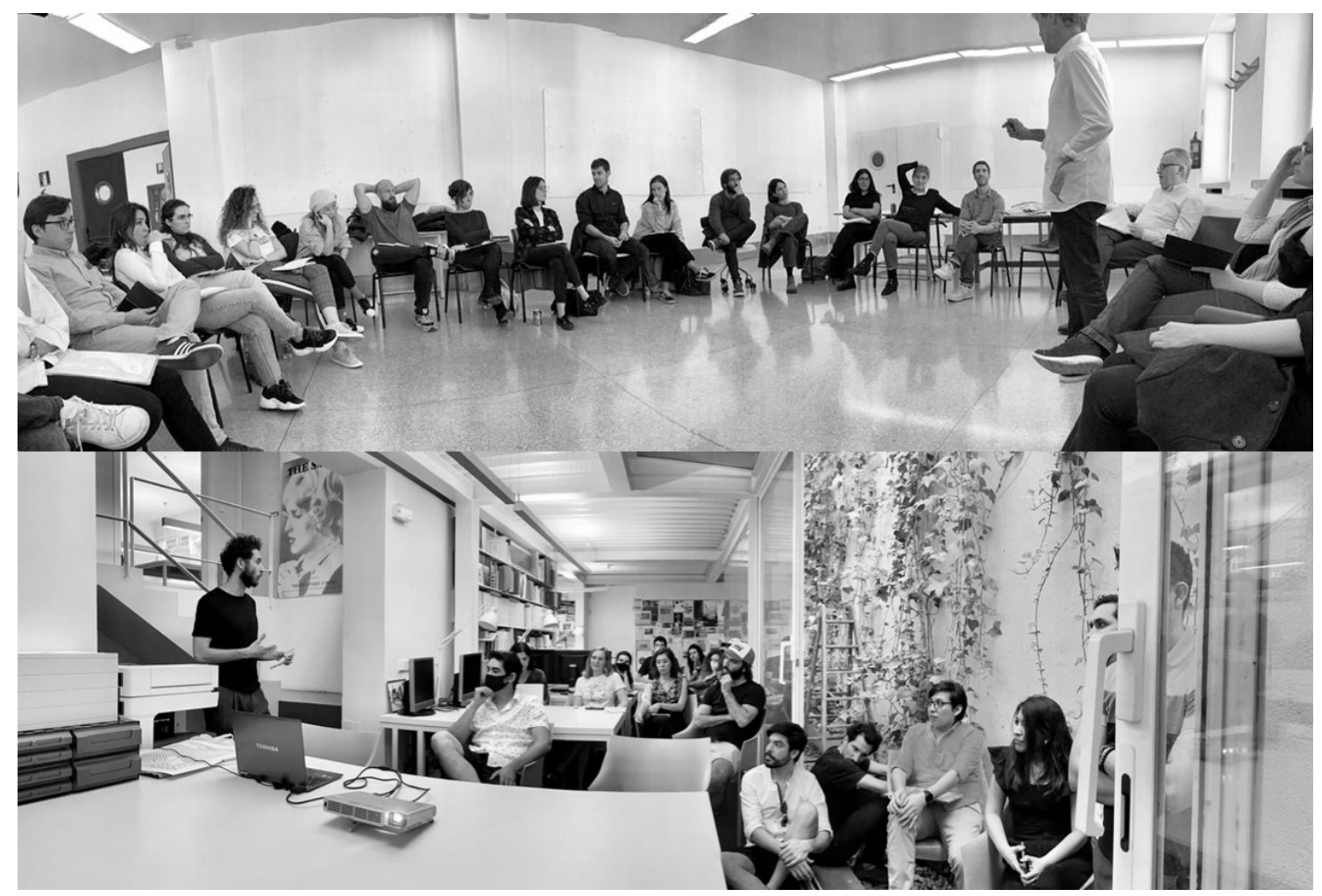

Fig. 5 y 6 Sesiones críticas de diálogo e intercambio de reflexiones de las fases 1 y 2 . Fuente: Minguito, A.P. (2021) —elaboración propia-

\subsection{Fase "acción"}

La segunda fase se aborda de una manera más dinámica, instando a cada estudiante/grupo a participar con una muestra de su agenda en una exposición con fecha y lugar de celebración, enunciada bajo el lema: "la agenda profesional tiempo después". Este evento de exposición final, al realizarse a puertas abiertas, representa una propia metodología activa en sí misma, ${ }^{15}$ más allá del inmediato carácter divulgativo que pueda tener (Domingo Santos, 2020).

Llegados a este punto, ya no basta con que el estudiante/grupo recopile referencias de oficinas con una vía de actuación similar a la de cada agenda. Sino que ha de proponer, idear y llevar a la práctica - de manera verídica o mediante la postproducción de documentación técnica o audiovisual que lo asemeje-, la presentación de cada agenda como si de una práctica de oficina real se tratara. ${ }^{16}$

De esta manera, se lleva a cabo un traslado de la base pedagógica a través de un orden lógico predeterminado: estimulando un primer asentamiento de los conceptos teóricos fundamentales que luego han de ser percibidos de forma clara y rotunda en la práctica desarrollada.

\footnotetext{
15 Valorando la experiencia desde una pedagogía experimental y abierta, las exposiciones docentes se convierten en herramientas de innovación docente y de transferencia del conocimiento para el estudiantado y la sociedad en general. Por lo que el hecho de establecer un diálogo continuo fomentado a raíz de la propia exposición, hace que ella misma se convierta en un instrumento didáctico de investigación: una metodología activa abierta a los procesos de trabajo que se generan en torno a ella y a los lugares en los que se exhibe.

16 La muestra que ha de presentar cada estudiante/grupo debe ser un fiel reflejo de la puesta en práctica profesional de cada agenda: un reportaje fotográfico de una pequeña intervención llevada a cabo o de una hipotética obra construida — para las agendas más relacionadas con la profesión tradicional del arquitecto-, o bien una secuencia audiovisual de un evento concreto más acorde a las agendas enfocadas a vías curatoriales, representacionales o sociales; entre otras formas de aproximación.
} 
Esta exposición final (Fig. 7 y 8) llevada a cabo permite contrastar la heterotopía ${ }^{17}$ de las distintas agendas planteadas. Con el apoyo de documentación física y digital, se establece un diálogo continuo entre profesorado y estudiantes, en el que se plantea un enfoque invertido de análisis de cada agenda: se incita a todo el estudiantado a la interpretación del material elaborado por cada grupo, para llegar a la identificación y determinación de los principios fundamentales trabajados en cada una de las agendas. Esto da lugar a la elaboración de un pensamiento conjunto de reflexión y argumentación, en vez de a una mera exposición de resultados.

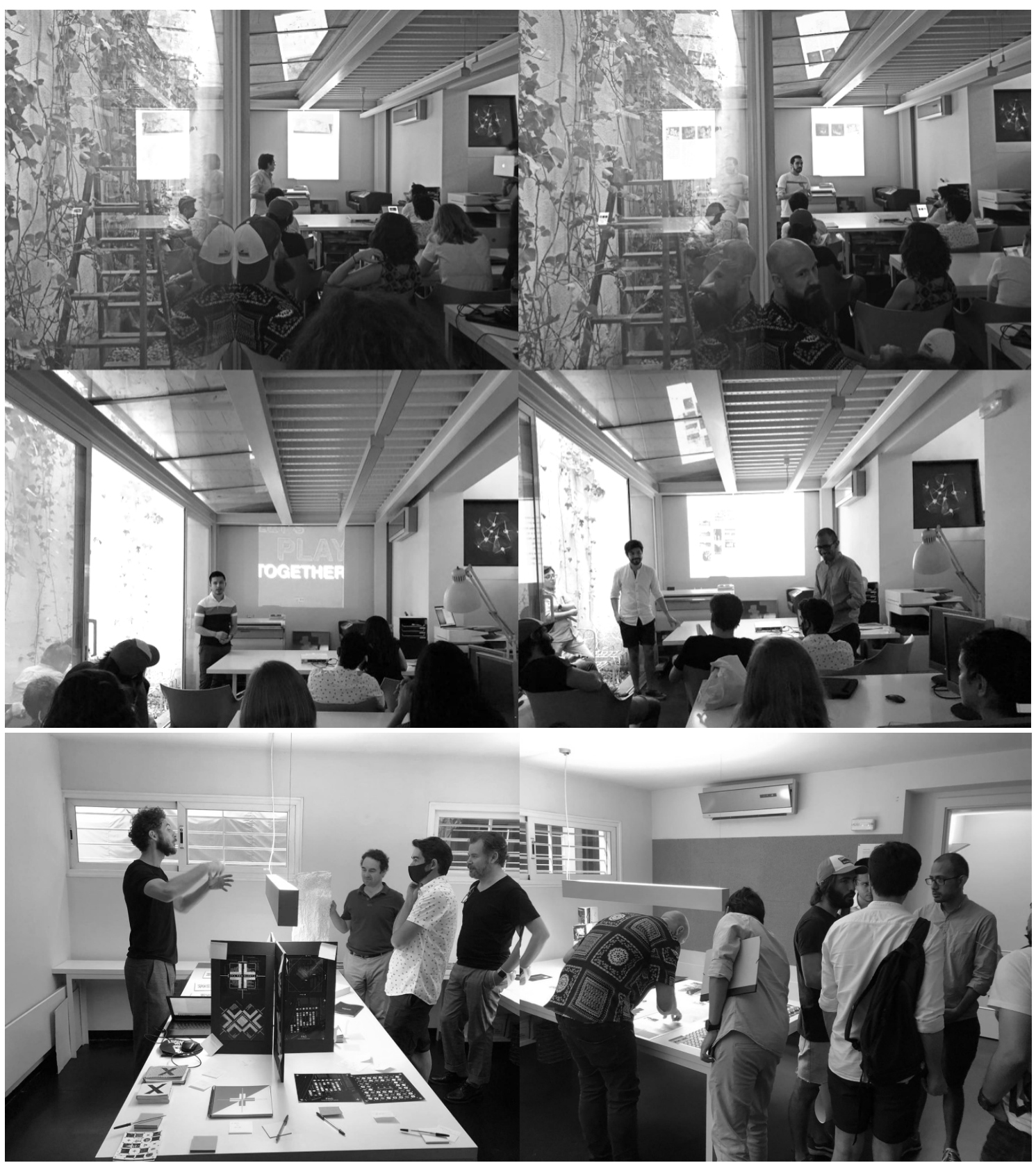

Fig. 7 y 8 Exposición final audiovisual y de diálogo continuo de intercambio de inquietudes en torno al material físico elaborado. Fuente: Minguito, A.P. (2021) —elaboración propia-

\footnotetext{
17 En referencia al concepto elaborado por el filósofo Michel Foucault para describir ciertos espacios culturales, institucionales y discursivos que de alguna manera son "otros": inquietantes, intensos, incompatibles, contradictorios o transformadores.
} 


\section{Renovación sin relegar a la tradición. [Análisis de resultados]}

La lectura trasversal global que se extrae de la experiencia llevada a cabo, parte de la lectura de la subfase de colaboración entre los estudiantes para la formación de grupos de trabajo. El desarrollo de la agenda de forma individual iguala prácticamente al número de grupos con dos socios en el equipo. La conclusión es directa: los estudiantes prefieren asumir más carga de trabajo a la hora de sacar adelante cada agenda, que invertir más tiempo y dedicación en llevar a cabo sesiones de consenso e intercambio de decisiones con un número mayor de asociados.

Aquí se realiza un apunte de mejora para futuras ediciones: con el propósito de no perder la riqueza desarrollada en el trabajo individual de definición de la "identidad" propia de cada estudiante, y al mismo tiempo ser partícipe de la riqueza obtenida en las dinámicas de consenso que se generan cuando se lleva a cabo una definición de agenda grupal, resulta pertinente realizar un reajuste en la estructuración del seminario. Aprovechando la duración anual del mismo, se propone llevar a cabo la experiencia docente de forma "duplicada", esto es, abarcándola a través de dos vías complementarias: inicialmente, estableciendo durante el primer cuatrimestre la definición de una agenda individual para cada estudiante (poniendo en marcha ambas fases teórica y práctica); seguidamente, repitiendo la experiencia durante el segundo cuatrimestre, pero esta vez de forma grupal. Así, sí que sería interesante comparar los resultados obtenidos en las dos vías experimentadas, a fin de sacar conclusiones aplicables, que además valoren el modo de trabajo más óptimo con el que sacar adelante un proyecto.

Asimismo, seguir manteniendo el seminario de posgrado en un formato reducido de estudiantes, estaría justificado (con los beneficios y virtudes que de ello se obtienen) ${ }^{18}$ ya que se "duplicarían" los resultados de las muestras obtenidas sobre los que establecer relaciones, comparaciones y conclusiones que aplicar a otras experiencias docentes o ediciones del seminario venideras.

\subsection{Ocho agendas alternativas}

Para realizar una valoración completa y a la vez concisa del material elaborado sobre las distintas agendas en la presente edición del seminario, es necesario evaluar ambas fases (teoría y práctica) conjuntamente. A grandes rasgos, se desarrollan un total de ocho agendas con diferentes enfoques profesionales:

- agenda tradicional

- agenda objetual

- agenda analítica

- agenda corporate ${ }^{19}$

- agenda efímera ${ }^{20}$

- agenda ecológica

- agenda minimalista

- agenda representacional

Cada agenda es bautizada y definida por el estudiante/grupo, sin mediación determinante del profesorado (Fig. 9).

\footnotetext{
18 El hecho de que un seminario de posgrado cuente con un número bastante ajustado de estudiantes, permite llevar a cabo la fase práctica de la experiencia en formatos de pequeños coloquios de argumentación, que sustituyen a las ancestrales exposiciones individuales y sesiones críticas por parte del profesorado.

19 Del anglicismo "corporate": corporativo, empresarial, colectivo.

20 Que se diluye en el tiempo como una metáfora que da cabida a nuevos valores a instaurar y transmitir a la sociedad
} 


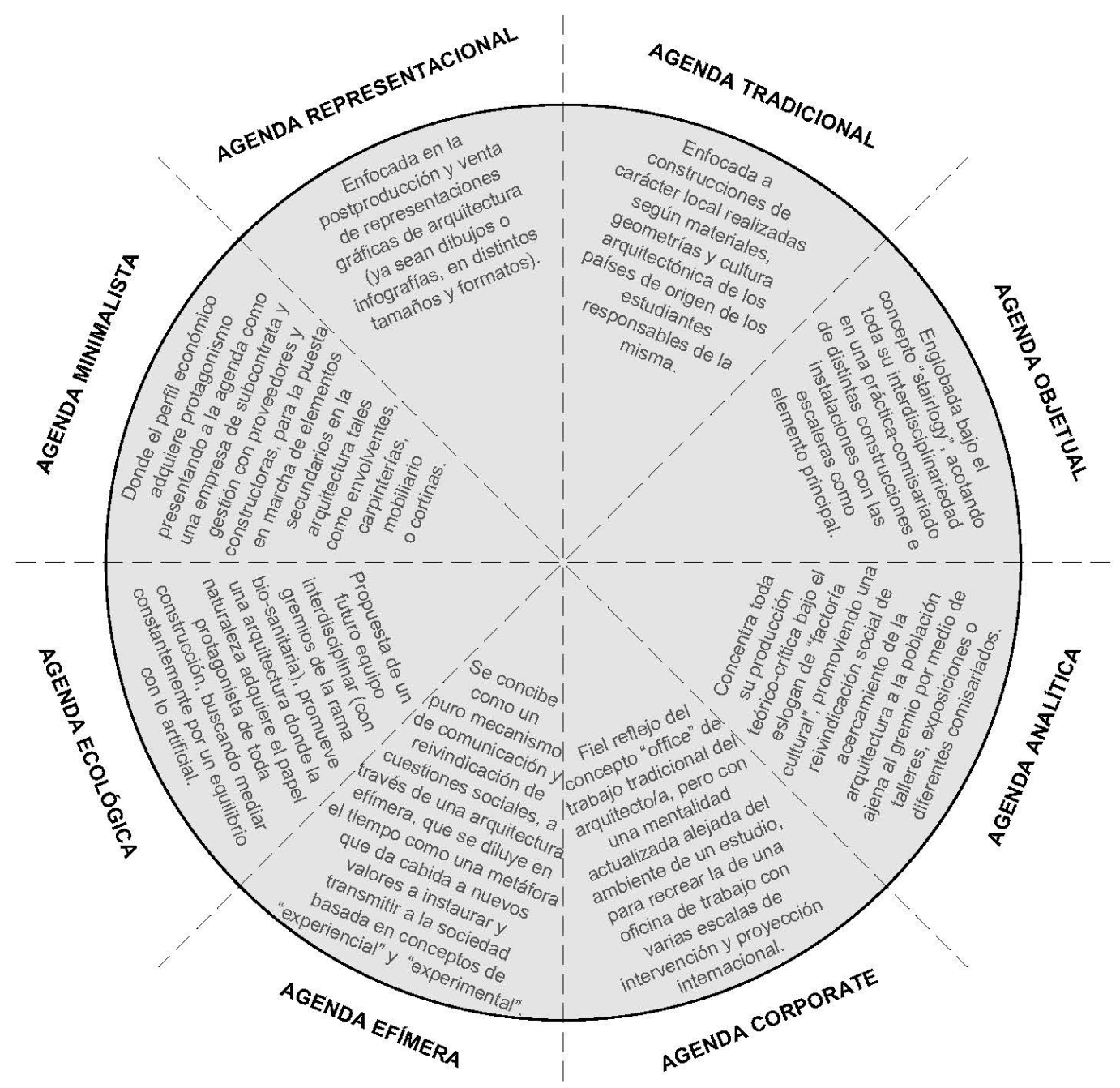

Fig. 9 Círculo relacional de agendas desarrolladas por los estudiantes en la experiencia. Fuente: Minguito, A.P. (2021) —elaboración propia-

Las lecturas trasversales de análisis del material producido (Fig 10-17), y los diagramas de relaciones entre las distintas agendas (Fig. 18 y 19), sentencian que tan solo una cuarta parte de los estudiantes plantea como primera opción profesional la basada en el principio tradicional del construir (la agenda tradicional, propiamente dicha, y la agenda "corporate"), concibiendo la construcción como una entidad en sí misma con varias fases de proyecto, y una cultura e imagen propias. Curiosamente, el enfoque profesional más compartido demanda un marco de actuación más transdisciplinar y, al mismo tiempo, más acotado. Se promueven perfiles profesionales especializados en elementos menores de la arquitectura (las escaleras de la agenda objetual, o la mentalidad "kitchen" de la agenda minimalista), o que buscan incluir al homónimo natural como elemento de igual en el ensamblaje arquitectónico (como la agenda ecológica). Otros roles del arquitecto trabajados demandan una atención específica a la vía de renovación de la "imagen" que es transmitida de la arquitectura (como la agenda representacional), o a la utilización de la misma como mecanismo de expresión -ya sea de reivindicación de valores sociales aprovechando la arquitectura efímera como instrumento de comunicación (como la propia agenda efímera), o llevando a cabo un análisis teórico-crítico de la repercusión social del papel de la arquitectura a través del comisariado de exposiciones o talleres que recuperan el tradicional legado teórico de análisis arquitectónico, pero desde un punto de vista renovado, con un enfoque más encauzado hacia el "por y para la sociedad" (como la agenda analítica)—. 


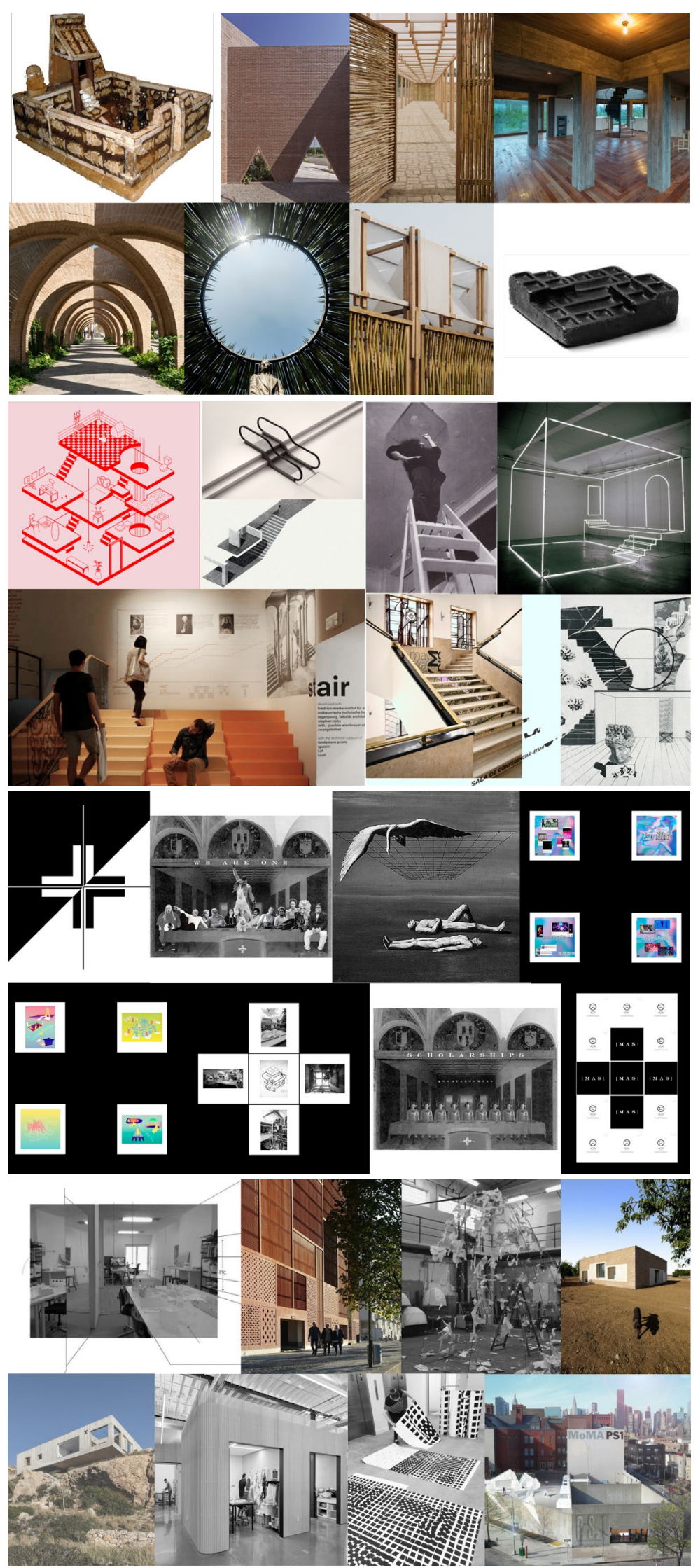

Fig. 10, 11, 12 y 13 Imágenes resumen del material producido por los estudiantes de la agenda tradicional, agenda objetual, agenda analítica y agenda corporate. Fuente: Minguito, A.P. (2021) —elaboración propia- 

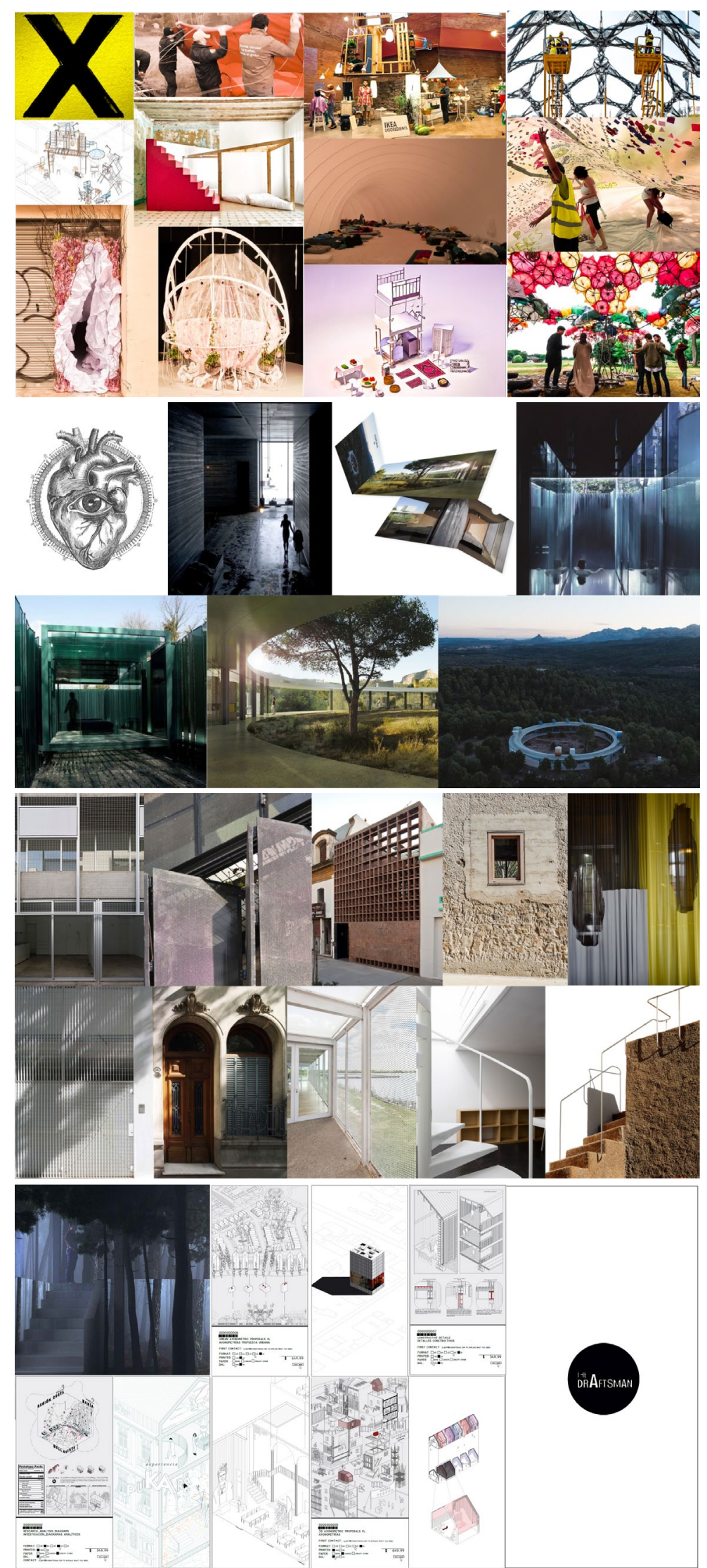

Fig. 14, 15, 16 y 17 Imágenes resumen del material elaborado por los estudiantes de la agenda efímera, agenda ecológica, agenda minimalista y agenda representacional. Fuente: Minguito, A.P. (2021) —elaboración propia- 

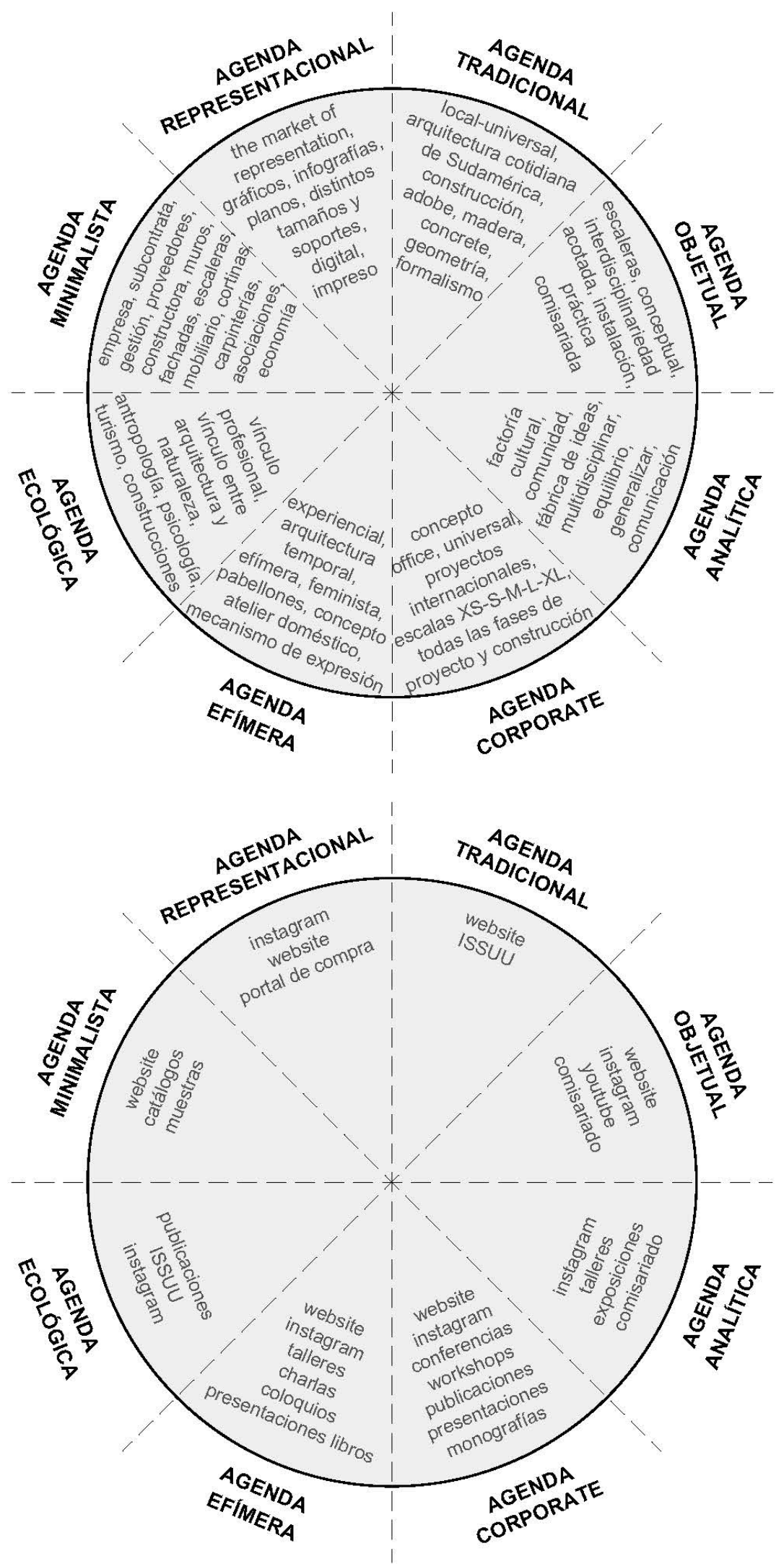

Fig. 18 y 19 Círculos relacionales de los "keywords" o conceptos clave trabajados en agenda, y de los medios de difusión y comunicación utilizados según la demanda temática de cada una de las agendas desarrolladas.

Fuente: Minguito, A.P. (2021) —elaboración propia- 
Cabe mencionar que, en los perfiles profesionales resultantes, sorprende la ausencia del rol del arquitecto como mediador en entornos participativos, o de agendas relacionadas con programas humanitarios o perfiles más especializados en cuestiones técnicas. Es preciso aclarar que el profesorado en ningún momento fomenta el encauzamiento de las agendas hacia algún objetivo en concreto, sino que da total libertad al estudiante para elegir. Por ello, sólo cabe cuestionarse si el análisis del resultado final obtenido se debe a lo ajustado de la muestra o a que verdaderamente los objetivos e intereses actuales se alejan de estas temáticas, encauzándose en otras más divulgativas y de interacción multidisciplinar.

\section{Hacia una docencia transdisciplinar [Conclusiones]}

La propuesta final de la comunicación induce a plantear tres preguntas que derivan de esta experiencia y a las que ha de enfrentarse la docencia de la arquitectura hoy en día: ¿sigue siendo la figura del arquitecto/a tradicional la del perfil profesional más demandado dentro de la disciplina de Arquitectura? ¿Hacia dónde se están perfilando los nuevos intereses del rol del arquitecto a día de hoy? En definitiva, ¿hacia dónde se encamina dicho campo profesional y qué tiene de consonancia con lo que verdaderamente se inculca en las Escuelas de Arquitectura? ${ }^{21}$

El contenido desarrollado en esta investigación práctica resulta relevante para poner en crisis la propia base misma de la enseñanza tal y como la conocemos hasta ahora, y conseguir provocar un importante debate sobre qué consideramos que abarca o ha de abarcar la palabra arquitectura, y qué debemos enseñar en las escuelas. Sin duda, gran parte del desarrollo de inquietudes y reflexiones que dan lugar a la capacidad múltiple de respuesta que muestran los estudiantes -y por extensión, los arquitectos-, es debido a su formación en gran medida multidisciplinar al abarcar conocimientos técnicos, artísticos y humanísticos. Por ello, resulta vital plantear y debatir qué cambios son sustanciales de experimentar las programaciones docentes para actualizar los contenidos que se inculcan a los debates contemporáneos que demanda la sociedad actual, para la que los estudiantes han de salir preparados y dar respuesta.

A raíz de la experiencis llevada a cabo, se puede discernir que es necesario enfatizar en la mejora de la formación actual del arquitecto en elementos que aumenten su capacidad de respuesta frente a los posibles mercados de trabajo. ${ }^{22}$ Concluyendo que, teniendo en cuenta la palpable demanda del estudiante por una orientación profesional más multidisciplinar y pormenorizada, habría que replantear un enfoque alternativo de la profesión desde la perspectiva docente, fomentando la creación de una mayor oferta de seminarios u asignaturas optativas o de especialización, ${ }^{23}$ donde se invite al estudiante a plantear los nuevos enfoques de agendas que demanda el verdadero rol del arquitecto a día de hoy.

\footnotetext{
${ }^{21}$ El objetivo último es encontrar una respuesta práctica en futuras comunicaciones o investigaciones que puedan derivarse de la actual.

22 Inculcar mayores capacidades de organización y planificación no sólo de las fases proyectuales, sino que incluyan campos como la economía de empresa, o las exigencias normativas de un producto u oferta; incitar al estudiante a manejar herramientas de difusión y divulgación para convertir propuestas de proyecto - muchas de ellas introvertidas y no comprensibles por personas ajenas a la profesiónen productos reconocibles y comercializables en el mercado laboral; y, sobre todo, mostrar al estudiante la posibilidad real de abrir el campo de abanicos de especialidades y salidas profesionales no solo dentro del entorno disciplinar, sino abarcando otros gremios, donde la perspectiva de trabajo de un perfil con la formación del arquitecto resulta meramente no solo necesaria, sino bastante enriquecedora.

${ }^{23}$ Con grupos reducidos a modo de talleres no solo de posgrado, sino que puedan ser elección del estudiante de últimos cursos de grado igualmente. Llegando a conseguir, incluso, un entorno aún más enriquecedor al promover el coincidir dentro del mismo grupo de taller una mayor heterogeneidad de perfiles, donde arquitectos titulados, otros con experiencia en el mundo laboral, y estudiantes aún en formación intercambien puntos de vista para enfocar la creación o el planteamiento de cuál es la agenda arquitectónica a la que enfocar su rol profesional.
} 


\section{Bibliografía}

AGUIRRE, P. (2015). "The Century of the Self" en Crítica y metacomentario, 1 de septiembre de 2015. <http://www.xn--crticaymetacomentario-u7b.net/search?q=the+century+of+the+self> [Consulta: 23 julio de 2021]

ASOCIACIÓN DE ACADEMIAS DE LA LENGUA ESPAÑOLA. Diccionario de la lengua de la Real Academia Española. < https://dle.rae.es/diccionario> [Consulta: 14 de junio de 2021]

CARRETERO, A. (2016). "Statement arquitectónico y statement ideológico" en Diario El Estado Mental, julio 2016, <https://elestadomental.com/diario/statement-arquitectonico-y-statement-ideologico> [Consulta: 16 junio de 2021]

DOMINGO SANTOS, J.; MORENO ÁlVAREZ, C.; y GARCÍA PÍRIZ, T. (2020). "Exposiciones docentes. Didáctica, transferencia e innovación en el ámbito académico" en Jornadas de Investigación Docente en Arquitectura 2020. Málaga. Disponible en <https://revistes.upc.edu/index.php/JIDA/article/view/9416> [Consulta: 02 de febrero de 2021]

GROPIUS, W. (1966). La nueva arquitectura y La Bauhaus. Buenos Aires: Editorial Lumen.

GUARDIOLA-VÍLLORA, A. y PÉREZ-GARCÍA, A. (2017). "El estudiante universitario responsable de su propio aprendizaje" en Jornadas de Investigación Docente en Arquitectura 2017. Sevilla. Disponible en <https://revistes.upc.edu/index.php/JIDA/article/view/5245> [Consulta: 05 de septiembre de 2021]

LÁZARO, C. "Aprendemos Juntos". Youtube: <https://youtu.be/5WnjvtvuzVA> [Consulta: 13 mayo de 2019] LUQUE, E. (2020). “Encuentros de pedagogía” en Edumeet. Madrid, ETSAM UPM, 11 de mayo de 2020.

MASDÉU, M. (2018). "Educando a la nueva generación de arquitectos: de las TICs a las TEPs" en Jornadas de Investigación Docente en Arquitectura 2018. Zaragoza. Disponible en < https://revistes.upc.edu/index.php/JIDA/article/view/5451> [Consulta: 20 de septiembre de 2020]

MONTANER, J.M. (2015). La condición contemporánea de la arquitectura. Barcelona: editorial Gustavo Gili. PIÑóN, H. (2006). Teoría Del Proyecto. Cataluña: Universidad Politécnica de Cataluña.

ROTMAN, S. (2014). "Debates en torno del espacio educativo moderno. Relecturas del texto: The New School. Das Neue Schulhaus. La Nouvelle Ecole" en Arquisur Revista. Universidad Nacional del Litoral, octubre $2014, \mathrm{~N}^{\circ} 4(5)$, p. 52-63.

SOLÀ-MORALES DE, I. et al. (2000). Introducción a la arquitectura, conceptos fundamentales. Barcelona: Edicions UPC.

VV.AA. (2005). Collins Spanish Dictionary. Nueva York: HarperCollins Publishers.

WICK, R. (1993). Pedagogía de la Bauhaus. Madrid: Alianza Editorial. 